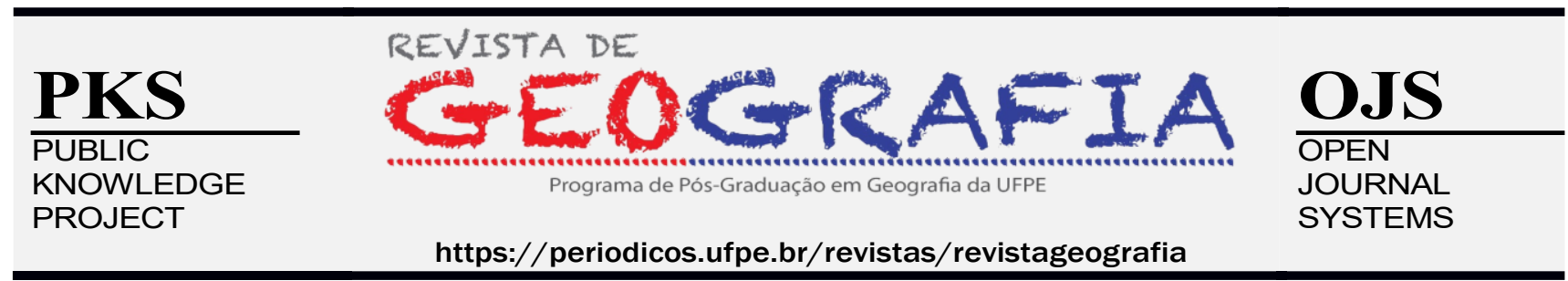

\title{
POLÍTICAS PÚBLICAS PARA O CAMPO: UM ESTUDO SOBRE A ATUAÇÃO DO PRONAF NA REGIÃO GEOGRÁFICA IMEDIATA DE PAU DOS FERROS/RN
}

\author{
Stênio Maia Estevam ${ }^{1}$, Alcimária Fernandes da Silva ${ }^{2}$, Cícero Nilton Moreira da Silva ${ }^{3}$
}

${ }^{1}$ Doutorando em Geografia pela Universidade Estadual do Ceará (PropGeo/UECE), E-mail: steniopinheiromaia@hotmail.com,ORCID: https://orcid.org/0000-0001-9292-4507

${ }^{2}$ Doutoranda em Geografia pela Universidade Federal da Paraíba (PPGG/UFPB), E-mail: alcimariafernandes@hotmail.com,ORCID: https://orcid.org/0000-0002-7525-1918

${ }^{3}$ Doutor Professor do Curso de Geografia da Universidade do Estado do Rio Grande do Norte (UERN), E-mail: ciceronilton@yahoo.com.br,ORCID: https://orcid.org/0000-0001-6773-7451

Artigo recebido em 06/07/2021 e aceito em 18/09/2021

\begin{abstract}
RESUMO
Este trabalho se constitui em um estudo sobre a atuação do PRONAF no âmbito da Agricultura Familiar, problematizando assim, a atuação das políticas públicas agrícolas (no caso estudado, o Programa Nacional de Fortalecimento da Agricultura Familiar) e sua materialização na Região Geográfica Imediata de Pau dos Ferros, Rio Grande do Norte. Para tanto, a metodologia consistiu na revisão de literatura buscando o suporte teórico em autores como Azevedo (2012), Mattei (2014), Brasil e Locatel (2012), Nunes (2015), Aquino e Lacerda (2015), dentre outros. A pesquisa ancorou-se em dados secundários, tendo sido utilizado como fonte de pesquisa o site da Diretoria de Gestão Estratégica, Monitoramento e Avaliação (DGMA), responsável por disponibilizar um painel com as políticas da Secretaria Especial de Agricultura Familiar e do Desenvolvimento Agrário (SEAD), em que podemos ter acesso às informações necessárias sobre o referido programa, considerando o recorte temporal de 2013 a 2018. Através dos dados obtidos foi possível perceber a presença significativa de estabelecimentos da agricultura familiar nessa localidade e o significativo volume de operações de crédito do PRONAF obtido pelos agricultores familiares nesse período, bem como a prioridade dada ao crédito para investimento nas atividades em vez do custeio de atividades produtivas. Percebemos ainda uma queda significativa no número de operações de crédito no ano de 2017, o que pode ter relação com os retrocessos políticos e a insegurança econômica vivenciada pelo país.
\end{abstract}

Palavras-chave: Agricultura Familiar; Políticas Públicas; PRONAF. 


\title{
PUBLIC POLICIES FOR THE COUNTRYSIDE: A STUDY ON PRONAF'S PERFORMANCE IN THE IMMEDIATE GEOGRAPHIC REGION OF PAU DOS FERROS/RN
}

\begin{abstract}
This paper is a study of the performance of PRONAF in the context of Family Farming, thus problematizing the performance of agricultural public policies (in this case, the National Program for the Strengthening of Family Farming) and its materialization in the Immediate Geographic Region of Pau dos Ferros, Rio Grande do Norte. To this end, the methodology consisted of a literature review seeking theoretical support from authors such as Azevedo (2012), Mattei (2014), Brasil and Locatel (2012), Nunes (2015), Aquino and Lacerda (2015), among others. The research was anchored in secondary data, using as a research source the website of the Directorate of Strategic Management, Monitoring and Evaluation, responsible for providing a panel with the policies of the Special Secretariat for Family Agriculture and Agrarian Development, where we can access the necessary information about the program, considering the time frame from 2013 to 2018. Through the data obtained, it was possible to notice the significant presence of family farming establishments in this location and the significant volume of PRONAF credit operations obtained by family farmers in this period, as well as the priority given to credit for investment in activities rather than the funding of productive activities. We also noticed a significant drop in the number of credit operations in the year 2017, which may be related to the political setbacks and economic insecurity experienced by the country.
\end{abstract}

Keywords: Family Agriculture. Public Policies. PRONAF.

\section{POLÍTICAS PÚBLICAS PARA EL CAMPO: UN ESTUDIO SOBRE EL DESEMPEÑO DEL PRONAF EN LA REGIÓN GEOGRÁFICA INMEDIATA DE PAU DOS FERROS/RN}

\begin{abstract}
RESUMEN
Este trabajo constituye un estudio sobre el desempeño del PRONAF en el contexto de la Agricultura Familiar, problematizando así el desempeño de las políticas públicas agrícolas (en el caso estudiado, el Programa Nacional de Fortalecimiento de la Agricultura Familiar) y su materialización en la Región Geográfica Inmediata de Pau dos. Ferros, Rio Grande do Norte. Por tanto, la metodología consistió en una revisión de la literatura buscando apoyo teórico en autores como Azevedo (2012), Mattei (2014), Brasil y Locatel (2012), Nunes (2015), Aquino y Lacerda (2015), entre otros. La investigación se basó en datos secundarios, y como fuente de investigación se utilizó el sitio web de la Dirección de Gestión Estratégica, Monitoreo y Evaluación (DGMA), responsable de brindar un panel con las políticas de la Secretaría Especial de Agricultura Familiar y Desarrollo Agrario (SEAD), en la cual podemos tener acceso a la información necesaria sobre el programa, considerando el marco temporal de 2013 a 2018. A través de los datos obtenidos se pudo percibir la presencia significativa de establecimientos de agricultura familiar en esta localidad y el volumen significativo de las operaciones crediticias del PRONAF obtenidas por los agricultores familiares durante este período, así como la prioridad otorgada al crédito para la inversión en actividades frente al costo de las actividades productivas. También notamos una caída significativa en el número de operaciones de crédito en 2017, lo que puede estar relacionado con los reveses políticos y la inseguridad económica que vive el país.
\end{abstract}

Palabras clave: Agricultura familiar. Políticas públicas. PRONAF. 


\section{INTRODUÇÃO}

As políticas públicas podem ser entendidas como uma forma utilizada pelo Estado no intuito de responder aos direitos da sociedade. Rua (1998, p. 01), a esse respeito, salienta que "Uma Política Pública geralmente envolve mais do que uma decisão e requer diversas ações estrategicamente selecionadas para implementar as decisões tomadas". Existe um grande número de políticas públicas, neste trabalho nos interessa as políticas públicas agrícolas, especificadamente, aquela voltada para agricultura familiar, como é o caso do PRONAF.

A agricultura familiar foi ao longo do tempo negligenciada pelo Estado, que pouca atenção despendeu a essa categoria tão relevante. Somente na década de 1990 ocorre a criação do PRONAF, que, para Azevedo (2012), constitui-se em um reconhecimento da agricultura familiar como um segmento do setor público. Até mesmo a denominação conceitual do agricultor familiar era outra, já que os mesmos eram conhecidos através de outras denominações, de acordo com as realidades locais/regionais, como produtor de subsistência, produtor familiar, pequeno agricultor, lavrador, dentre outras.

Brasil e Locatel (2012) afirmam que o Programa citado surgiu como linha de crédito de custeio, em 1995. Todavia, em 1996 passou a ser trabalhado enquanto um Programa de Governo, vinculado à Secretaria de Desenvolvimento Rural do Ministério da Agricultura (SDR/MDA). De 1999 até 2016, o PRONAF passou a integrar ação direta da Secretaria de Agricultura Familiar (SAF), do Ministério do Desenvolvimento Agrário (MDA). Atualmente, com a extinção do MDA, aquele passou a fazer parte da Secretaria Especial de Agricultura Familiar e do Desenvolvimento Agrário (SEAD), vinculada à Casa Civil da Presidência da República e vem sendo vítima de cortes em seu orçamento, o que pode vir a comprometer os avanços e resultados que esse programa vem logrando desde a sua criação, tendo em vista que, mesmo diante dos entraves burocráticos e da própria distribuição dos recursos entre as regiões brasileiras, o PRONAF tem contribuído com o desenvolvimento da agricultura familiar no campo brasileiro.

Em meio aos avanços, as ameaças e os retrocessos vivenciados pelo PRONAF, o trabalho hora proposto tem como objetivo analisar a atuação dessa política pública na Região Geográfica Imediata de Pau dos Ferros/RN.

Nessa perspectiva, buscaremos trazer, após essa introdução, os procedimentos metodológicos utilizados no decorrer do trabalho, seguido do referencial teórico e da análise qualitativa dos dados 
coletados de maneira secundária. Por último, teceremos as considerações finais, elencando reflexões sobre a aplicabilidade dessa política no recorte espacial estudado.

\section{METODOLOGIA}

Este trabalho foi desenvolvido nas seguintes etapas: primeiro, efetuou-se um levantamento bibliográfico, que possibilitou um melhor entendimento sobre o desenvolvimento das políticas públicas agrícolas, em especial, do PRONAF, buscando autores como Azevedo (2012), Mattei (2014), Brasil e Locatel (2012), Nunes (2015), Aquino e Lacerda (2015), dentre outros. Na etapa seguinte, tivemos como suporte para a busca de dados secundários o site da Diretoria de Gestão Estratégica, Monitoramento e Avaliação (DGMA), responsável por disponibilizar um painel com as políticas da Secretaria Especial de Agricultura Familiar e do Desenvolvimento Agrário (SEAD). Após a coleta dos dados, esses foram analisados e sistematizados, apresentando algumas das características dos estabelecimentos agropecuários e, principalmente, a atuação do PRONAF nos municípios que compõem a Região Geográfica Imediata de Pau dos Ferros.

Na conclusão, buscamos elencar algumas reflexões sobre a atuação dessa política, enfatizando elementos que precisam da atuação sistemática dos atores locais, como o poder público de maneira geral, bem como instituições que poderiam contribuir com o êxito dessa política como a própria Empresa Brasileira de Pesquisa Agropecuária (EMBRAPA) e as universidades locais no encaminhamento de ações que possam ir de encontro aos anseios dos beneficiários.

\section{POLÍTICAS PÚBLICAS AGRÍCOLAS: ALGUMAS CONSIDERAÇÕES}

Tratando-se de Política Agrícola no Brasil, cumpre aqui destacar, com base em Mueller (2010), que o primeiro órgão responsável pela execução dessa política em nosso país surge em 1860, com a denominação de Secretaria dos Negócios da Agricultura, Comércio e Obras Públicas. Em 1906, a referida secretaria passa a ser denominada de Ministério da Agricultura, Indústria e Comércio, assumindo assim, o comando do setor público agrícola, voltado para a normatização de produção vegetal e animal, fomento à pesquisa e a condução de políticas microssetoriais para a agropecuária, captação e gestão de recursos. Para Mueller (2010, p. 17): 
Os interesses da área econômica em relação à agricultura, nem sempre coincidiam com os de organizações importantes do setor público agrícola. A área econômica estava focada na modernização urbano-industrial e nos desajustes macroeconômicos do período, e dos países que atribuía à agricultura eram o de assegurar o abastecimento interno de alimentos e insumos agropecuários e o de contribuir na geração de divisas para atenuar desequilíbrios do setor externo.

Na década de 1960, através do Estatuto da Terra, Lei 4. 504/64, ocorre a regulamentação da política agrícola no território brasileiro. Nesse Estatuto, enfatiza-se:

Art. $1^{\circ}$ Esta Lei regula os direitos e obrigações concernentes aos bens imóveis rurais, para os fins de execução da Reforma Agrária e promoção da Política Agrícola. $\S 1^{\circ}$ Considera-se Reforma Agrária o conjunto de medidas que visem a promover melhor distribuição da terra, mediante modificações no regime de sua posse e uso, a fim de atender aos princípios de justiça social e ao aumento de produtividade.

$\S 2^{\circ}$ Entende-se por Política Agrícola o conjunto de providências de amparo à propriedade da terra, que se destinem a orientar, no interesse da economia rural, as atividades agropecuárias, seja no sentido de garantir-lhes o pleno emprego, seja no de harmonizá-las com o processo de industrialização do país.

Percebemos a amplitude dessa Lei, tendo em vista que ela envolve aspectos do agrícola e do agrário e que, portanto, faz-se necessário à sua diferenciação, já que Política Agrícola diferencia-se de Política Agrária.

A primeira se constitui em um conjunto de ações voltadas para o planejamento, o financiamento e o seguro da produção e compõe a base da Política Agrícola do atual Ministério da Agricultura, Pecuária e Abastecimento (MAPA). A segunda, objetiva resolver os problemas estruturais do setor agrícola, tais como o acesso à terra, irrigação, logística, e também estabelecer um conjunto de princípios fundamentais e disciplinar regras do desenvolvimento do setor agrícola, conforme Guanziroli (2014). Assim, compreendemos que a Política Agrícola iria cuidar de questões conjunturais, como a produção e os preços, por exemplo, enquanto que a política agrária iria buscar uma transformação a longo prazo do espaço agrário, como é o caso da Reforma Agrária.

Posterior ao Estatuto da Terra, em 17 de Janeiro 1991, ocorre a criação da Lei No 8.171 que dispõe, especificadamente, sobre a Política Agrícola brasileira, definindo os objetivos e as competências institucionais, bem como os recursos, as ações e os instrumentos dessa política voltada para as atividades de cunho agropecuário, agroindustrial, pesqueiro e florestal. Ela é abrangente e envolve vários aspectos relacionados à sua operacionalização no campo, como: o Planejamento Agrícola, a Pesquisa Agrícola, a Assistência Técnica e Extensão Rural, a Proteção ao Meio Ambiente e Conservação dos Recursos Naturais, a Defesa Agropecuária, a Informação Agrícola, a Produção, a 
Comercialização, o Abastecimento, a Armazenagem, o Associativismo e Cooperativismo, o Crédito Rural, o Seguro Agrícola, a Habitação Rural, a Eletrificação Rural, a Mecanização Agrícola, dentre outros.

Desse modo, as políticas públicas agrícolas são implementadas nos territórios, buscando estimular a produção (preços, crédito, juros, seguro, formação de estoques, exportação, compras) e também a promoção da distribuição da riqueza da agricultura. Com base nisso, Nunes (2007, p. 03) salienta que a:

Orientação dessas políticas é dada pelo papel que se espera que a agricultura cumpra em um dado momento histórico (liberar mão-de-obra, baratear o custo da cesta básica, promover as exportações de determinados produtos, garantir a segurança alimentar, fortalecer a agricultura familiar ou patronal.

Mesmo diante de todos os entraves, é notório a importância da Política Agrícola em um país. Nunes (2007, p. 04 e 05) traz uma lista de elementos que comprovam a importância dessa ferramenta, já que contribui diretamente para:

1. Reduzir as instabilidades provocadas pelo mercado e clima;

2. Favorecer o investimento nas atividades agrícolas;

3. Elevar a produção e a produtividade agrícola;

4. Reduzir os custos de produção por unidade de mercadoria produzida (kg ou saca), devido à redução no custo do crédito, da assistência técnica, tecnologias, uso de novas tecnologias de produção e máquinas que aumentam a produtividade do trabalho, etc.;

5. Reduzir os custos dos alimentos ao consumidor final. Isso também pode acontecer com os demais produtos agrícolas e florestais: fibras, energia (álcool, biodiesel) e madeira;

6. Democratizar o acesso ao crédito e às tecnologias entre os que têm dificuldade de acesso através dos mecanismos normais, facilitando sua inserção ao mercado;

7. Fazer frente à concorrência dos produtos agrícolas importados, mediante a redução dos custos de produção provocados pela própria política agrícola, através de barreiras tarifárias à importação e isenção de impostos à exportação;

8. Promover o desenvolvimento de determinados produtos agrícolas e técnicas de produção, que dependerá dos incentivos da política e do mercado;

9. Facilitar, pela disponibilidade de crédito, o acesso aos insumos e tecnologias colocados no mercado (adubos químicos, agrotóxicos, etc);

10. Facilitar a organização de cadeias produtivas, favorecendo também as indústrias; 11. Elevar a renda das famílias através do aumento da produção destinada à comercialização;

12. Diversificar as atividades rurais, estimulando atividades não-agrícolas ou parcialmente agrícolas (agroindústrias, turismo, etc); 
13. Incentivar e promover a segurança alimentar, pois do contrário pode contribuir para estimular apenas alguns produtos que possuem conjuntura de mercado mais favorável (soja, por exemplo);

14. Transferir renda - nesse caso, encontram-se os créditos com níveis de abatimento alto aos agricultores de baixa renda (Pronaf B, por exemplo, embora também estimule a produção);

15. Desenvolver outros setores da economia (indústria e serviços).

Os elementos acima não têm garantia de que de fato possam acontecer, mas são indicativos importantes nos resultados práticos de uma política pública agrícola, quando implantada.

Dentro da Política Agrícola, o crédito ${ }^{1}$ agrícola (pode ser entendido como um dos instrumentos da política agrícola) é muito importante para agricultores, pois ele pode contribuir de maneira significativa como subsídio nas atividades do campo e também na compra de equipamentos e rebanhos, e na construção de infraestruturas, como armazéns e cacimbão, dentre outros.

\section{DÉCADA DE 1990 E A CRIAÇÃO DO PRONAF}

Como enfatizado, a agricultura familiar foi negligenciada ao longo da história brasileira no que diz respeito à destinação de políticas públicas para esse segmento. Só na década de 1990 surge o PRONAF, sob a justificativa da importância da agricultura familiar no que alude à geração de emprego e à produção de alimentos.

De acordo com a concepção de Azevedo (2012), a criação do PRONAF evidencia, de certa forma, o reconhecimento da agricultura familiar como parte do setor público. Embora ainda existam problemas na sua operacionalização, por exemplo, aspectos burocráticos, ele tem contribuído para mudanças e conduzido melhorias no espaço agrário nacional.

\footnotetext{
${ }^{1}$ Sobre o Crédito Rural, um dos instrumentos da Política Agrícola, podemos observar os seguintes aspectos no Art. 48. $\mathrm{O}$ crédito rural, instrumento de financiamento da atividade rural, será suprido por todos os agentes financeiros sem discriminação entre eles, mediante aplicação compulsória, recursos próprios livres, dotações das operações oficiais de crédito, fundos e quaisquer outros recursos, com os seguintes objetivos:

I - estimular os investimentos rurais para produção, extrativismo não predatório, armazenamento, beneficiamento e instalação de agroindústria, sendo esta quando realizada por produtor rural ou suas formas associativas;

II - favorecer o custeio oportuno e adequado da produção, do extrativismo não predatório e da comercialização de produtos agropecuários;

III - incentivar a introdução de métodos racionais no sistema de produção, visando ao aumento da produtividade, à melhoria do padrão de vida das populações rurais e à adequada conservação do solo e preservação do meio ambiente;

IV - (Vetado).

V - Propiciar, através de modalidade de crédito fundiário, a aquisição e regularização de terras pelos pequenos produtores, posseiros e arrendatários e trabalhadores rurais;

VI - Desenvolver atividades florestais e pesqueiras.

VII - apoiar a substituição do sistema de pecuária extensivo pelo sistema de pecuária intensivo/

VIII - estimular o desenvolvimento do sistema orgânico de produção agropecuária.
} 
A implementação do PRONAF, em 1996, é, em certa medida, uma evidência da mudança de enfoque no processo de implementação das políticas públicas para o espaço rural brasileiro, pois, até o início dos anos de 1990, nenhuma política pública específica foi direcionada para a promoção da agricultura familiar. Vale salientar que até mesmo a denominação conceitual do agricultor familiar era outra, já que ele era conhecido por diversas outras denominações, de acordo com as realidades locais/regionais, a citar: produtor de subsistência, produtor familiar, pequeno agricultor, lavrador, dentre outras.

O PRONAF foi instituído de maneira oficial a partir do Decreto Presidencial No 1.946, de 28 de junho de 1996, no Governo do então Presidente Fernando Henrique Cardoso, com o intuito de apoiar o desenvolvimento rural, tendo como fundamento o fortalecimento da agricultura familiar. $\mathrm{O}$ Art. $1^{\mathrm{o}}$ da referida Lei vem mostrar que ele tem como finalidade possibilitar o desenvolvimento sustentável do segmento rural constituído pelos agricultores familiares, de modo a propiciar-lhes o aumento da capacidade produtiva, bem como a geração de empregos e a melhoria da renda.

Em documento oficial da antiga SAF/MDA ${ }^{2}$, denominado de "Cartilha de Acesso ao PRONAF 2011 - 2012" estão apresentados os grupos básicos do PRONAF, que são: A, A/C, B, C e Pronaf Agricultor Familiar. As linhas especiais do Pronaf são: Agroindústria, Mulher, Jovem, Semiárido, Agroecologia, Floresta, Eco, Mais alimentos. As linhas especiais para pessoas físicas e jurídicas são: custeio e comercialização de agroindústria familiar, e cotas-partes. Cada grupo está inserido em enquadramentos e possui finalidades específicas.

Dentro desse contexto, mesmo sabendo da importância dessa política no desenvolvimento do espaço agrário brasileiro contemporâneo, é notório a visualização das disparidades e os problemas de operacionalização da política pública do PRONAF, que acabam sendo influenciadas pelos vícios tradicionais da burocracia dos diferentes órgãos públicos. Isso, muitas vezes, afeta o acesso por parte dos agricultores familiares a serem beneficiados pelo Programa.

Mesmo com os problemas, dentre eles os burocráticos, sabemos da necessidade de uma Política Agrícola consistente que beneficie não só o agronegócio ou a agricultura patronal. É preciso lançar o olhar para os agricultores familiares, já que no decorrer da evolução das políticas agrícolas, em nosso país, a preocupação era integrar os agricultores na economia de escala voltados às grandes culturas, como o algodão, o café, a soja e o trigo.

É compreensível que devido a extensão territorial brasileira, seja marcante a diversidade, mas é sabido que os agricultores familiares necessitam de assistência, de forma que sejam atingidos os

\footnotetext{
${ }^{2}$ Secretaria federal extinta em 2016, junto à estrutura organizacional do Ministério do Desenvolvimento Agrário (MDA).
} 
princípios de igualdade no que tange à ação intervencionista do Estado. A conjuntura atual aponta para a questão de políticas direcionadas ao território.

O PRONAF, quando criado na década de 1990, exigia que os beneficiários do programa deveriam atender aos seguintes critérios: explorar parcela da terra na condição de proprietário, posseiro, arrendatário ou parceiro; residir na propriedade ou em local próximo; possuir no máximo quatro módulos fiscais de terra; não manter empregado permanente, admitindo-se a ajuda de terceiro; obter no mínimo $80 \%$ de sua renda através da exploração agropecuária ou extrativa de acordo com Maia, Bastos, Conti e Roitman (2012). Entretanto, tendo em vista a heterogeneidade dos agricultores familiares, muitos desses critérios tiveram que ser redimensionados para que viessem atender a grupos específicos de agricultores, pois, de acordo com Maia, Bastos, Conti e Roitman (2012, p. 182):

Uma vez delimitado o potencial público beneficiário (os ditos "pronafianos"), não se estabelecia qualquer distinção entre as famílias no que se refere ao rendimento que auferem. Não havia sequer um limite máximo de renda familiar anual para os possíveis beneficiários, bastando que eles se enquadrassem nas demais condições supramencionadas [...]. Na ausência de critérios que atentassem para essas especificidades, os recursos eram disponibilizados de forma indiscriminada, com as condições de financiamento sendo as mesmas para todos os possíveis beneficiários. O resultado inevitável foi uma seleção enviesada dos mutuários, concentrando aqueles de maior renda.

Dentro dessa conjuntura, podemos compreender um pouco sobre a concentração e disparidades na distribuição do crédito entre as regiões brasileiras. "Nos quatro primeiros anos-safra de vigência do programa, $65 \%$ do valor financiado foi destinado a produtores da Região Sul do país, justamente aquela que concentra os agricultores familiares com maior renda”. (MAIA, BASTOS, CONTI et al, 2012, p. 182). Essas disparidades regionais e entre os estados ainda não foram superadas de fato, pois Souza e Barbé (2014, p. 42) concluem que:

Entre 1998 e 2006 houve redistribuição dos recursos em favor dos municípios das regiões Nordeste e Sudeste, principalmente, mas também das regiões Norte e CentroOeste, e a desigualdade da distribuição total caiu [...]. Após 2006, o processo de piora na distribuição dos recursos esteve associado principalmente ao efeito composição, decorrente da forte queda na participação dos municípios nordestinos no montante total do crédito, paralela ao crescimento da parcela destinada aos municípios da Região Sul. 
A citação acima se refere à distribuição dos recursos, tendo em vista que o maior do montante se encontra concentrado na região Sul do país. Acredita-se que esse fato é reflexo da própria organização produtiva dos agricultores familiares dessa região; entretanto, no que concerne ao público potencial do PRONAF, ou seja, que está apto ao acesso ao crédito, o Censo Agropecuário (2006) mostrou que o maior número se encontra na região Nordeste $(50,82 \%)$.

\section{REGIÃO GEOGRÁFICA IMEDIATA DE PAU DOS FERROS/RN}

A Região Geográfica Imediata de Pau dos Ferros se encontra inserida no Rio Grande do Norte, sendo uma das onze regiões imediatas desse estado. Ela compõem a nova divisão regional do Instituto Brasileiro de Geografia (IBGE) (2017), que substitui as chamadas Microrregiões Geográficas, sendo composta por 34 municípios. Na figura 01, podemos observar a localização e a configuração dessa nova região geográfica:

Figura 01- Região Geográfica Imediata de Pau dos Ferros/RN

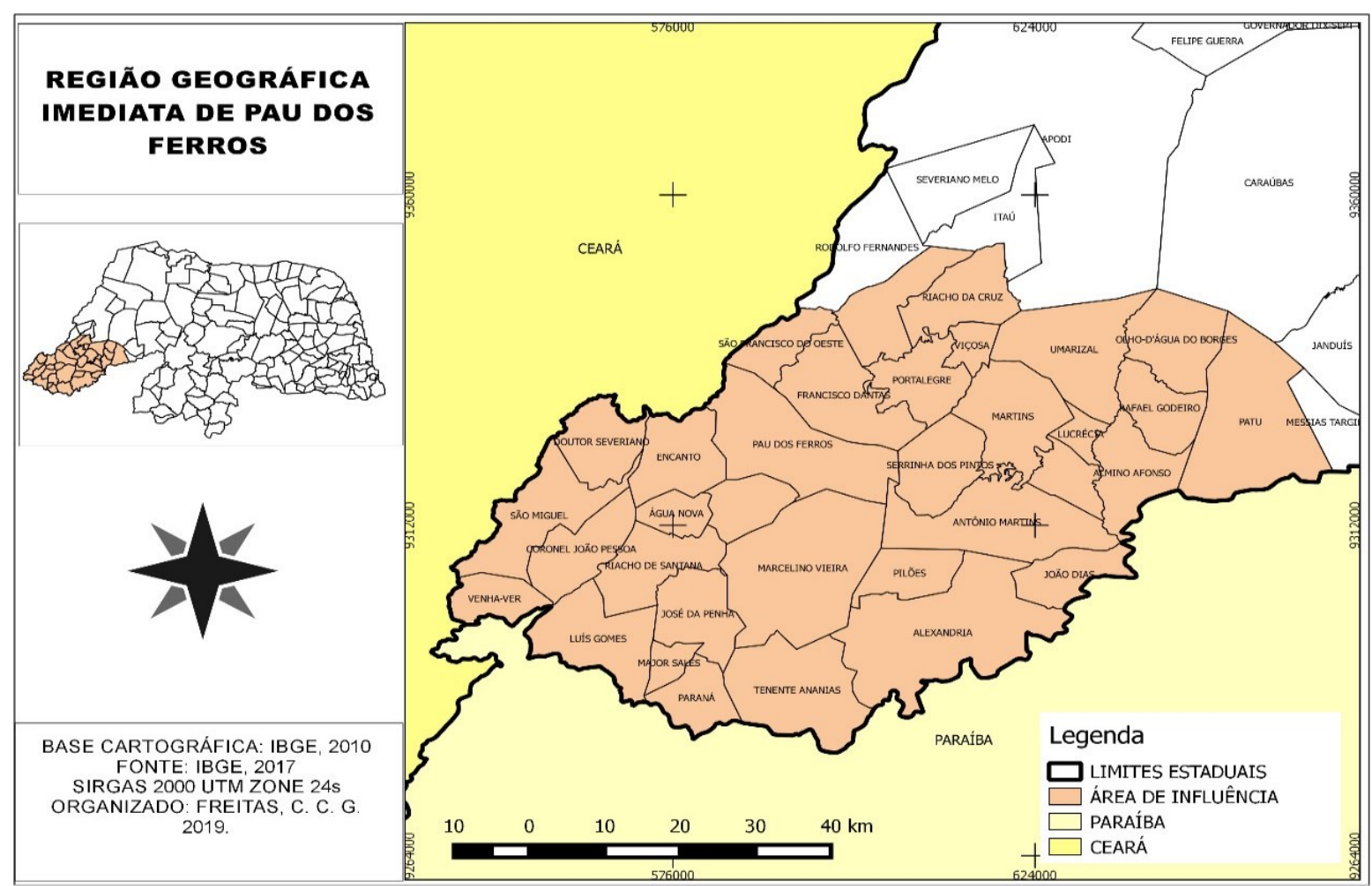

Fonte: IBGE, 2017 SIRGAS 2000 UTM ZONE 24S. Organização: FREITAS, C.C.G, 2019. 
Os municípios que compõem esse recorte espacial se encontram inseridos na região semiárida do Nordeste e, portanto, susceptíveis aos longos períodos de estiagem característicos das localidades com essas condições climáticas. Podemos enfatizar ainda, dentre tantas outras características, que, mesmo com essas peculiaridades propiciadas pelo clima, muitas pessoas tem como principal fonte de renda as atividades de cunho agropecuário para subsistência ou para comercialização em feiras locais, geralmente no próprio município em que residem ou em municípios vizinhos.

No gráfico 01, podemos conhecer o número de estabelecimentos agropecuários presentes nos municípios que compõem essa região:

Gráfico 01 - Número de estabelecimentos agropecuários nos municípios da Região Geográfica Imediata de Pau dos Ferros (2006)

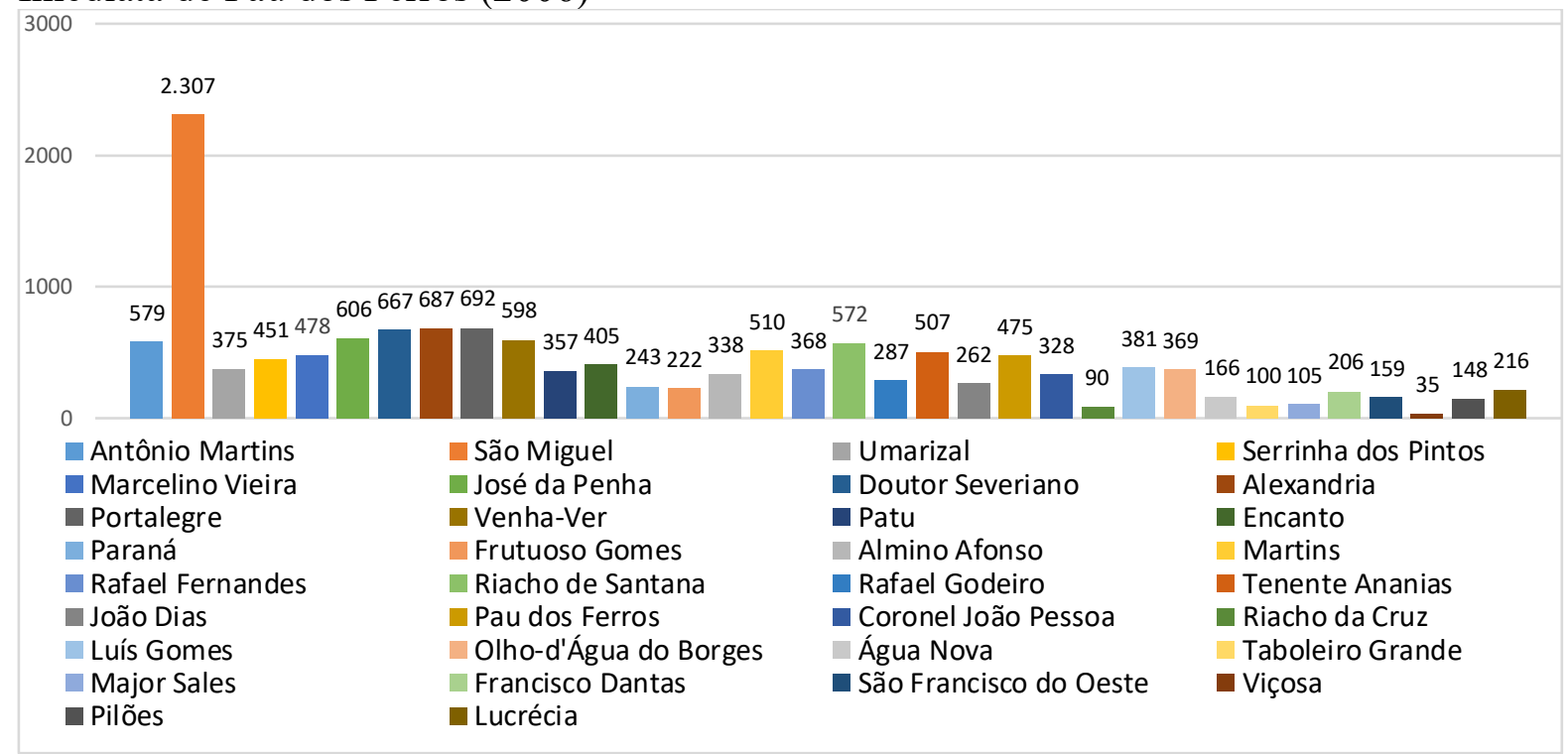

Fonte: Painel de Políticas da SEAD. Disponível em: <http://nead.mda.gov.br/politicas>. Acesso em: 19 Mai. 2019.

Dos estabelecimentos agropecuários apresentados no gráfico, mais de 50\% se caracterizam como sendo da agricultura familiar ${ }^{3}$. Municípios como São Miguel, Doutor Severiano, Lucrécia, Encanto, Rafael Fernandes, Olho d'água dos Borges, Coronel João Pessoa, Pau dos Ferros e São

\footnotetext{
${ }^{3}$ A Lei $n^{0} 11.326$, de 24 de julho de 2006, estabelece diretrizes para a formulação da Política Nacional da Agricultura Familiar e Empreendimentos Familiares Rurais e delimita o universo que compõem a agricultura familiar. O Art. 3o, considera agricultor familiar e empreendedor familiar rural aquele que pratica atividades no meio rural, atendendo, simultaneamente, aos seguintes requisitos:

I - não detenha, a qualquer título, área maior do que 4 (quatro) módulos fiscais;

II - utilize predominantemente mão-de-obra da própria família nas atividades econômicas do seu estabelecimento ou empreendimento;

III - tenha percentual mínimo da renda familiar originada de atividades econômicas do seu estabelecimento ou empreendimento, na forma definida pelo Poder Executivo

IV - dirija seu estabelecimento ou empreendimento com sua família.
} 
Francisco do Oeste possuem mais de $90 \%$ de seus estabelecimentos agropecuários que se enquadram na agricultura familiar. O município de Riacho da Cruz é uma exceção com relação aos outros municípios, tendo em vista que nele somente $42,22 \%$ são de caráter familiar.

Mesmo com o percentual elevado de estabelecimentos da agricultura familiar, é importante destacar o fato desses municípios serem formados por pequena extensão territorial. Na Tabela 01, podemos observar a área total dos estabelecimentos e a área dos estabelecimentos agropecuários da agricultura familiar em específico:

Tabela 01 - Área total dos estabelecimentos agropecuários (ha) e a área dos estabelecimentos da agricultura familiar (\%)

\begin{tabular}{|c|c|c|}
\hline MUNICÍPIOS & $\begin{array}{c}\text { ÁREA TOTAL DOS } \\
\text { ESTABELCIMENTOS } \\
\text { AGROPECUÁRIOS (HA) }\end{array}$ & $\begin{array}{l}\text { ÁREA DOS ESTABELECIMENTOS } \\
\text { DA AGRICULTURA FAMILIAR (\%) }\end{array}$ \\
\hline Antônio Martins & 22.892 & $41,96 \%$ \\
\hline São Miguel & 8.639 & $92,08 \%$ \\
\hline Umarizal & 17.924 & $40,34 \%$ \\
\hline Serrinha dos Pintos & 11.657 & $26,57 \%$ \\
\hline Marcelino Vieira & 30.543 & $38,55 \%$ \\
\hline José da Penha & 11.386 & $66,49 \%$ \\
\hline Doutor Severiano & 4.868 & $67,29 \%$ \\
\hline Alexandria & 32.570 & $43,95 \%$ \\
\hline Portalegre & 14.099 & $31,18 \%$ \\
\hline Venha-Ver & 4.822 & $74,10 \%$ \\
\hline Patu & 22.251 & $39,77 \%$ \\
\hline Encanto & 7.315 & $69,13 \%$ \\
\hline Paraná & 6.243 & $51,57 \%$ \\
\hline Frutuoso Gomes & 4.582 & $68,63 \%$ \\
\hline Almino Afonso & 9.711 & $53,62 \%$ \\
\hline Martins & 4.600 & $60,28 \%$ \\
\hline Rafael Fernandes & 5.501 & $83,41 \%$ \\
\hline Riacho de Santana & 8.862 & $68 \%$ \\
\hline Rafael Godeiro & 10.018 & $39,88 \%$ \\
\hline Tenente Ananias & 23.403 & $41,14 \%$ \\
\hline João Dias & 5.102 & $61,64 \%$ \\
\hline Pau dos Ferros & 16.812 & $52,23 \%$ \\
\hline Coronel João Pessoa & 7.374 & $56,18 \%$ \\
\hline Riacho da Cruz & 12.148 & $15,77 \%$ \\
\hline Luís Gomes & 11.582 & $43,68 \%$ \\
\hline Olho-d'água do Borges & 9.650 & $59,65 \%$ \\
\hline Água Nova & 4.304 & $46,50 \%$ \\
\hline Taboleiro Grande & 10.102 & $29,79 \%$ \\
\hline Major Sales & 3.064 & $38,23 \%$ \\
\hline Francisco Dantas & 15.852 & $35,76 \%$ \\
\hline São Francisco do Oeste & 6.068 & $73,70 \%$ \\
\hline Viçosa & 1.499 & $50,49 \%$ \\
\hline Pilões & 8.237 & $56,80 \%$ \\
\hline Lucrécia & 2.850 & $61,92 \%$ \\
\hline
\end{tabular}

Fonte: Painel de Políticas da SEAD. Disponível em: <http://nead.mda.gov.br/politicas>. Acesso em: 19 Mai. 2019. 
Aquino e Lacerda (2015), refletindo sobre as condições de reprodução econômica dos agricultores familiares pobres no semiárido brasileiro a partir de evidências do Rio Grande do Norte, chegamos à compreensão de que a reduzida quantidade de terras disponíveis para os agricultores, pode ser considerado como um dos principais fatores que diminuem as possibilidades deles garantirem a sobrevivência, a partir da exploração de atividades de cunho agropecuário. Embora ocorram esses entraves com relação à posse da terra e que impactam de forma negativa no desenvolvimento da agricultura familiar, a criação do PRONAF e com ele a possibilidade de obtenção de crédito pelos agricultores, constitui-se para os autores citados um avanço positivo no âmbito das políticas públicas.

\section{A ATUAÇão do PRONAF NA REgIão GEOGRÁfiCA IMEdiATA de PAU dos FERROS/RN}

No âmbito do Estado do Rio Grande do Norte, Azevedo (2012) faz uma análise da representatividade do PRONAF no que se refere à agricultura familiar. O autor leva em consideração o número de contratos e o volume de operações de crédito até o ano de 2006 e conclui que o número de operações tem aumentado. Azevedo (2012, p. 139-140) nos afirma que:

Ao analisarmos os dados do MDA (2006) percebemos que esses aumentos ocorreram, sobretudo, durante o governo Lula (2003-2006). Em 1999, 2000 e 2001, o número de contratos foi reduzido, com acirramento da disparidade regional Nordeste - Sul, ao passo que, a partir de 2002 houve aumentos contínuo e consideráveis tanto no número de contratos quanto no montante de recursos destinados ao Rio Grande do Norte.

Azevedo (2012, p. 140) conclui afirmando:

Os aumentos percentuais no número de contratos e no volume de recursos do PRONAF no Estado, no ano fiscal de 2005 em relação a 1999, foram 600\%, e 986\% respectivamente. Já no ano de 2005 em relação a 2002, o aumento foi $265 \%$, no número de contratos, e $448 \%$, no volume de recursos. Significa dizer que, em 2005, foram firmados 79.555 contratos contra 30.023 contraídos em 2002. Dessa forma, o volume de recursos do PRONAF elevou-se de aproximadamente, R\$33.000.000 para quase R\$ 148.000 .000 , o que implicou suavização das disparidades regionais, embora ainda permaneçam elevadas. 
Assim, com base no estudo do autor sobre o PRONAF, os resultados de sua presença como política pública têm impulsionado mudanças significativas, tanto para a região Nordeste como todo, e para o território potiguar em particular.

Esses resultados podem ser observados quando se considera a perspectiva de que muitos agricultores não tiveram ao longo do tempo o acesso a nenhum tipo de crédito. Com o acesso ao respectivo programa, eles têm a possibilidade de melhorar a infraestrutura do seu estabelecimento agropecuário e "[...] melhorias no padrão de consumo das famílias beneficiadas, com consequente melhorias nas condições de vida da população atingida, não obstante os diversos problemas existentes no setor" (AZEVEDO, 2012, p. 140).

Aproximando-se com as concepções de Azevedo (2012), o autor Aquino (2015), em artigo publicado no Jornal de Fato, Mossoró/RN, em 20 de Agosto de 2015, discutindo sobre os agricultores do semiárido potiguar, salienta que os agricultores familiares descapitalizados são maioria no território potiguar e "necessitam de terra, água, assistência técnica, crédito, tecnologias adaptadas aos ecossistemas microrregionais e melhores condições de infraestrutura social nas comunidades rurais, as quais, para eles, cumprem a dupla função de local de produção e de espaço de vida". O referido autor considera o apoio governamental uma forma de sanar ou amenizar as desigualdades socioeconômicas das populações que habitam as diversas áreas desse estado. Isso envolveria não somente ações emergenciais voltadas para o combate à seca que, embora tenham um papel importante no momento crítico de estiagem, não são capazes de condicionar melhorias sociais, bem como o acesso à cidadania por essas pessoas que vivem no meio rural potiguar.

Concordamos com a opinião do autor quando coloca que o apoio governamental é importante. No entanto, ressaltamos que o problema é mais complexo, tendo em vista que existem outros elementos, tais como: a baixa escolaridade, já que muitos agricultores têm apenas as séries iniciais ou nunca foram a escola; a limitada participação em associações junto aos outros moradores, dentre outros elementos, prejudicam o processo e que, devem ser sanados para que contribuam com o desenvolvimento da agricultura familiar.

Todavia, nos municípios que compõem a Região Geográfica Imediata de Pau dos Ferros, a atuação do PRONAF junto aos agricultores tem sido muito importante e não foge da perspectiva de análise dos autores citados, quando discutem a importância do PRONAF no âmbito estadual.

Para conhecermos essa realidade, consideraremos inicialmente o número de contratos referentes a essa política no decorrer dos últimos 05 anos, tabela 02: 
Tabela 02 - Número de contratos do PRONAF (de 2013 - 2018)

\begin{tabular}{|c|c|c|c|c|c|c|c|}
\hline MUNICÍPIOS & 2013 & 2014 & 2015 & 2016 & 2017 & 2018 & TOTAL \\
\hline Antônio Martins & 393 & 385 & 666 & 602 & 409 & 458 & 2.913 \\
\hline São Miguel & 411 & 627 & 638 & 490 & 274 & 453 & 2.893 \\
\hline Umarizal & 300 & 223 & 213 & 265 & 265 & 310 & 1.576 \\
\hline Serrinha dos Pintos & 334 & 471 & 526 & 584 & 242 & 287 & 2.444 \\
\hline Marcelino Vieira & 249 & 213 & 388 & 380 & 201 & 378 & 1.809 \\
\hline José da Penha & 346 & 397 & 393 & 342 & 200 & 356 & 2.034 \\
\hline Doutor Severiano & 290 & 272 & 373 & 453 & 197 & 399 & 1984 \\
\hline Alexandria & 429 & 533 & 679 & 745 & 182 & 426 & 2.994 \\
\hline Portalegre & 358 & 309 & 349 & 350 & 167 & 230 & 1.763 \\
\hline Venha-Ver & 229 & 266 & 346 & 289 & 150 & 191 & 1.471 \\
\hline Patu & 220 & 172 & 239 & 296 & 148 & 201 & 1.276 \\
\hline Encanto & 248 & 277 & 374 & 329 & 140 & 204 & 1.572 \\
\hline Paraná & 150 & 146 & 151 & 173 & 126 & 196 & 942 \\
\hline Frutuoso Gomes & 214 & 167 & 268 & 270 & 116 & 161 & 1.196 \\
\hline Almino Afonso & 152 & 153 & 191 & 206 & 116 & 96 & 914 \\
\hline Martins & 143 & 180 & 172 & 250 & 111 & 104 & 960 \\
\hline Rafael Fernandes & 160 & 234 & 244 & 207 & 108 & 160 & 1.113 \\
\hline Riacho de Santana & 129 & 239 & 282 & 259 & 104 & 244 & 1.250 \\
\hline Rafael Godeiro & 160 & 128 & 101 & 127 & 100 & 134 & 750 \\
\hline Tenente Ananias & 139 & 106 & 191 & 234 & 93 & 211 & 974 \\
\hline João Dias & 175 & 182 & 138 & 198 & 92 & 137 & 922 \\
\hline Pau dos Ferros & 143 & 190 & 184 & 193 & 82 & 112 & 923 \\
\hline Coronel João Pessoa & 358 & 258 & 199 & 191 & 82 & 113 & 1.201 \\
\hline Riacho da Cruz & 104 & 64 & 77 & 141 & 75 & 67 & 528 \\
\hline Luís Gomes & 167 & 67 & 83 & 111 & 75 & 40 & 543 \\
\hline Olho-d'água dos Borges & 170 & 123 & 80 & 144 & 65 & 125 & 707 \\
\hline Água Nova & 73 & 73 & 140 & 102 & 52 & 66 & 506 \\
\hline Taboleiro Grande & 64 & 106 & 107 & 84 & 46 & 58 & 465 \\
\hline Major Sales & 85 & 102 & 52 & 84 & 46 & 63 & 432 \\
\hline Francisco Dantas & 64 & 209 & 74 & 142 & 38 & 157 & 684 \\
\hline São Francisco do Oeste & 35 & 82 & 101 & 89 & 34 & 80 & 421 \\
\hline Viçosa & 41 & 35 & 44 & 51 & 32 & 30 & 233 \\
\hline Pilões & 139 & 168 & 127 & 142 & 24 & 101 & 701 \\
\hline Lucrécia & 79 & 163 & 226 & 280 & 15 & 209 & 972 \\
\hline
\end{tabular}

Fonte: Painel de Políticas da SEAD. Disponível em: <http://nead.mda.gov.br/politicas>. Acesso em: 05 Jun. 2019.

Através da análise da tabela é possível perceber um número significativo de contratos obtidos pelos agricultores no decorrer desse período, o que recai positivamente sobre a própria dinâmica econômica desses municípios.

José da Penha, São Miguel, Alexandria, Serrinha dos Pintos e António Martins se sobressaem no número de contratos em virtude de serem municípios com um significativo contingente de estabelecimentos agropecuários da agricultura familiar. Podemos perceber ainda uma variação no número de contratos em todos os municípios no decorrer do recorte temporal considerado, mas chama a atenção uma queda significativa, no ano de 2017, na maior parte dos municípios, seguida de uma 
elevação tímida no ano de 2018. Esse fato pode ter relação com o fator da insegurança, devido a conjuntura econômica e política que o país, desde meados dos anos 2010.

Entretanto, vale salientar que, como o crédito do PRONAF pode ser destinado tanto ao custeio (Gráfico 04) de atividades produtivas como investimos (Gráfico 03), no ano de 2018, os agricultores familiares desses municípios deram prioridades aos investimentos.

Gráfico 03 - Número de contratos de crédito do PRONAF destinados ao custeio (2018)

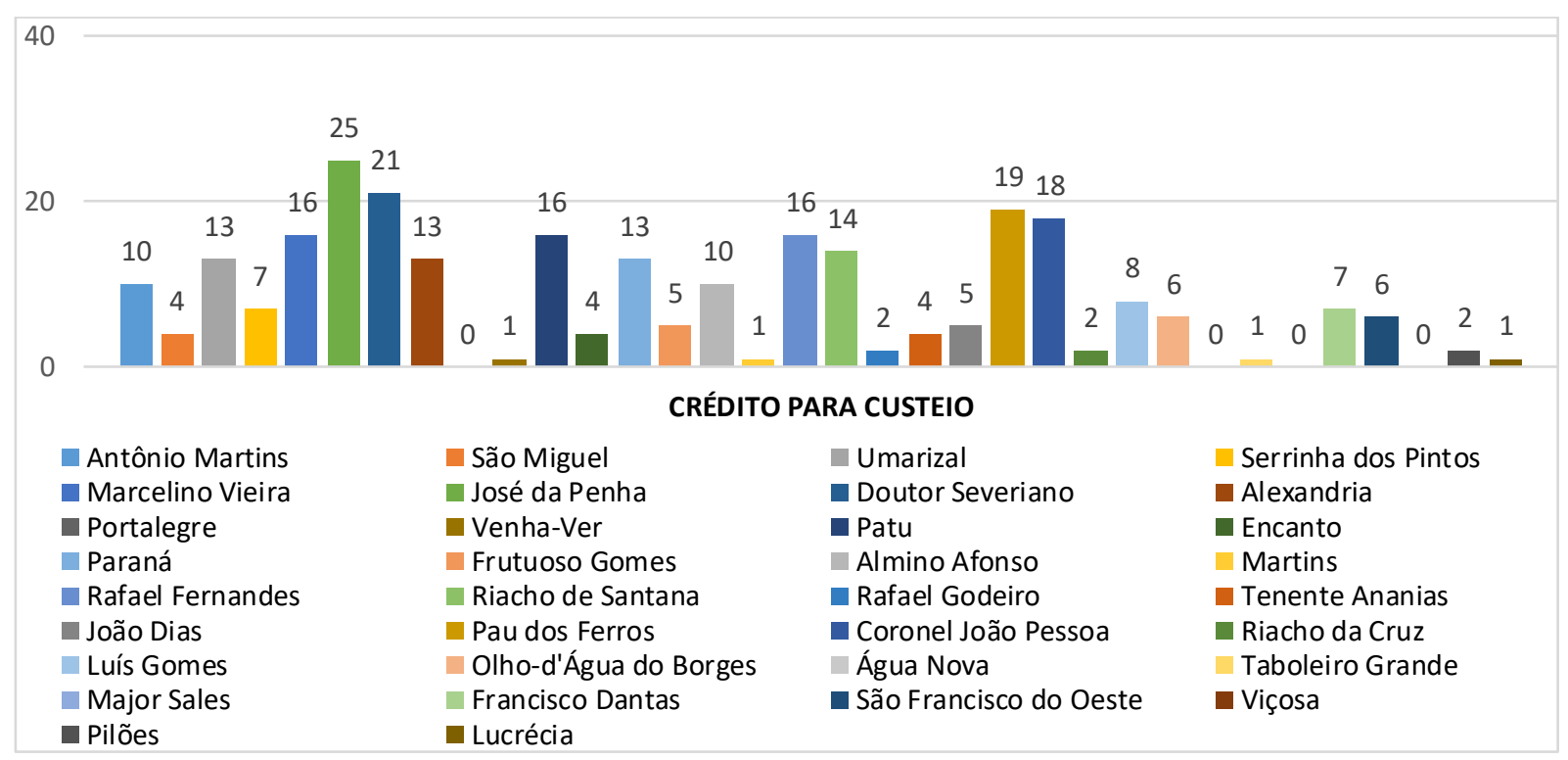

Fonte: Painel de Políticas da SEAD. Disponível em: <http://nead.mda.gov.br/politicas>. Acesso em: 19 Mai. 2019.

Gráfico 04 - Número de contratos de crédito do PRONAF destinados a investimento (2018)

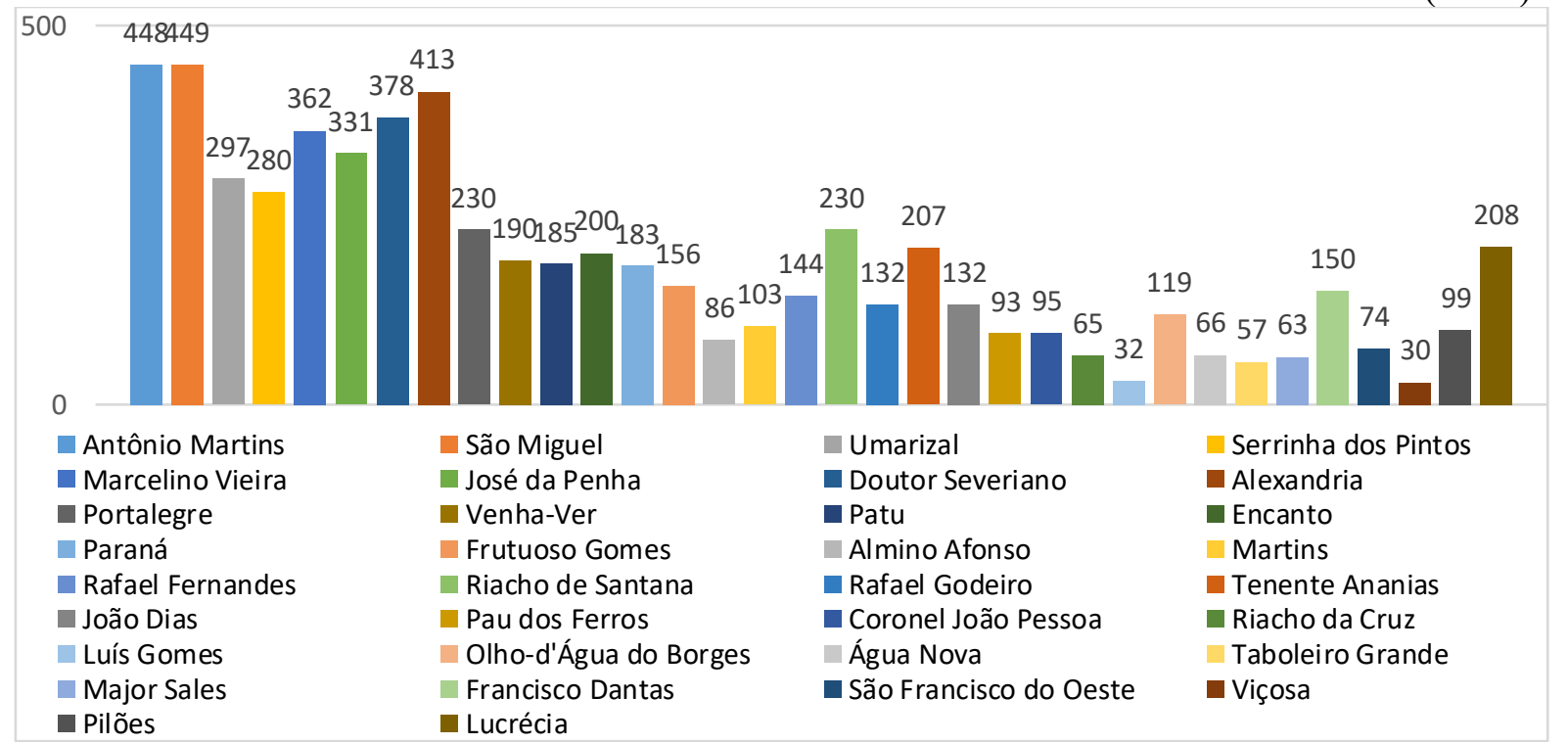

Fonte: Painel de Políticas da SEAD. Disponível em: <http://nead.mda.gov.br/politicas>. Acesso em: 19 Mai. 2019. 
O crédito para investimento pode ser aplicado na compra de equipamentos para serem utilizados nos estabelecimentos agropecuários, bem como a construção de espaços para animais, acondicionar e transportar a produção. São elementos infraestruturais que propiciam a melhoria das atividades produtivas no ano posterior.

Em trabalho desenvolvido por Silva (2017), nos municípios que compõem a área de abrangência do Banco do Nordeste - Agência de Pau dos Ferros ${ }^{4}$ são discutidas as dificuldades enfrentadas pelos agricultores familiares do PRONAF, em específico enfatizado a realidade dos pronafianos que acessam a linha de crédito B.

De acordo com a autora:

Dentre as dificuldades enfrentadas pelos agricultores do Pronaf B podemos constatar, a partir de depoimentos dos mesmos, o acesso às documentações junto ao Instituto de Defesa e Inspeção Agropecuária do RN - IDIARN. Essa instituição é responsável, no âmbito do Estado do RN, pela inspeção e fiscalização agropecuária. Desse modo, quando a atividade que o agricultor almeja envolve a criação de animais, necessita desse órgão para a emissão de documentos, como a Guia de Transporte Animal (GTA) e também a inspeção ao estabelecimento agropecuário (SILVA, 2017, p. 106).

Por outro lado, a referida autora traz também o impacto do crédito com base na visão dos beneficiários, mostrando que é nítido na fala dos agricultores familiares entrevistados a importância do crédito para o desenvolvimento de suas atividades, sendo que muitos deles veem o crédito como uma forma de investir na sua propriedade, comprando materiais para construção de cercas, bovinos e também como possibilidade de melhoria de renda. Contudo, considerando a política agrária nacional a partir do Governo do então Presidente da República Jair Bolsonaro - o qual assumiu a presidência em janeiro de 2019, esse tem desempenhado ações que vão na contramão dessa política voltada para agricultura familiar.

De acordo com a Rede Brasil Atual, ocorreu no ano de 2019, suspensão do repasse de verbas para investimentos do Programa. Dessa forma, em vez de ter sido repassado 30 bilhões para agricultura familiar, o valor chegou apenas a 24 bilhões do orçamento planejado para 2018/2019. Além disso, ainda não existe uma definição concreta sobre os rumos do programa para os próximos anos, o que acaba gerando muitas incertezas com relação a essa política.

\footnotetext{
${ }^{4}$ Os municípios que compõem a área de abrangência do BNB estão inseridos na Região Geográfica Imediata de Pau dos Ferros.
} 
Em nota pública, a Confederação Nacional dos Trabalhadores e Trabalhadoras da Agricultura Familiar do Brasil (CONTRAF), repudia as ações empreendidas negativamente à agricultura familiar, que mais uma vez passa a ser negligenciada, sendo os agricultores menores os mais prejudicados, por exemplo, os assentados da "reforma agrária".

Para a CONTRAF, a redução no volume de crédito vai dificultar ou mesmo excluir pessoas da atividade rural. "O impacto é direto e gera exclusão maior de famílias. Só poderão fazer investimentos com recursos próprios quem tiver condições, se tiver frustração com intempéries climáticas, não vai ter seguro. Afeta até a permanência no campo".

\section{CONCLUSÃO}

Este trabalho se constitui em um estudo sobre a atuação do PRONAF na Região Geográfica Imediata de Pau dos Ferros, problematizando assim, a atuação das políticas públicas agrícolas (no caso estudado, o Programa Nacional de Fortalecimento da Agricultura Familiar -PRONAF) e sua materialização sobre o território. Dessa forma, nesta parte do trabalho, buscaremos tecer algumas considerações referente à problemática, apresentando uma leitura com base nos dados secundários obtidos no site da Diretoria de Gestão Estratégica, Monitoramento e Avaliação (DGMA).

O aporte teórico possibilitou uma reflexão acerca das políticas públicas, com ênfase nas políticas agrícolas para agricultura familiar, o PRONAF. Assim, trazendo para a realidade estudada, foi possível perceber o número significativo de operações de crédito realizadas no período de 2013 a 2018, mesmo apresentando oscilações e uma queda considerável em 2017, o que mostra a importância de políticas dessa natureza para os agricultores familiares, hoje ameaçada pelos cortes de verbas do Governo Bolsonaro.

Foi possível conhecer o número de estabelecimentos agropecuários nos municípios que compõem o recorte espacial estudado e também perceber a concentração de terras nessas localidades, em que os agricultores familiares tem um restrito esbelecimento agropecuário, o que os limita em relação ao desenvolvento de suas atividades.

Diante da realidade estudada, destacamos não só a importância política do PRONAF, mas a necessidade da formulação de uma agenda pública no intuito de fortalecer esse programa com outros agentes de políticas no semiário, como: Apoio à captação de água de Chuva e outras tecnologias sociais de acesso à água - Programa de Cisternas, considerando a problemática de disponibilidade de água e a necessidade de investimentos relacionados à construção de cacimbão e poços artesianos para 
dessedentação animal, tendo em vista os sucessivos períodos de estiagem vivenciados nessa localidade; a necessidade de estratégias conjuntas de ampliação da cobertura da Assistência Técnica e Extensão Rural e o próprio apoio de instituições, como a Empresa Brasileira de Pesquisa Agropecuária (EMBRAPA) e as universidades locais.

Dessa maneira, espera-se que a leitura do texto sirva para despertar o interesse de novos pesquisadores e para a reflexão do público interessado no assunto. Assim sendo, é imprescindível que todos tenham consciência da importância da temática, e que esta pesquisa possa se constituir num instrumento para auxiliar na busca por novos conhecimentos e alternativas de desenvolvimento para o campo brasileiro contemporâneo.

\section{REFERÊNCIAS}

AQUINO, J. R. A dualidade entre os agricultores do semiárido potiguar. Jornal de Fato, Mossoró RN, p. 2-2, 20 Ago. 2015.

AQUINO, J. R; LACERDA. M. A. D. Magnitude e condições de reprodução econômica dos agricultores familiares pobres no semiárido brasileiro: evidências a partir do Rio Grande no Norte. RESR. Piracicaba - SP, Vol. 52, 2015.

AQUINO, J. R; LACERDA. M. A. D. Magnitude e condições de reprodução econômica dos agricultores familiares pobres no semiárido brasileiro: evidências a partir do Rio Grande no Norte. RESR. Piracicaba - SP, Vol. 52, 2015.

AZEVEDO. F. F. O Programa Nacional de Fortalecimento da Agricultura familiar e as transformações da agropecuária no Rio Grande do Norte: uma análise do período 1995 -2005. In: CHELOTTI. M. C. (Org.). Geografia agrária e diversidades territoriais do campo brasileiro. Uberlândia: Assis editora, 2012, p. 133-160.

BAIARDI, A. Gênese e evolução da agricultura familiar: desafios na realidade brasileira e as particularidades do semiárido. Rev. Econ. NE, Fortaleza, v. 45, p. 124-135, 2014.

BRASIL, L. K. B; LOCATEL, C. D. Atuação do estado enquanto normatizador do território: espacialização do programa de aquisição de alimentos no rio grande do norte. Disponível em: http://www.lagea.ig.ufu.br/xx1enga/anais_enga_2012/eixos/1404_1.pdf. Acesso em: 07 Jun. 2019.

GUANZIROLI, C. E. Evolución de la Política Agrícola Brasileña: 1980-2010. Mundo Agrário, 15 (29), agosto 2014. ISSN 1515-5994.

MAIA, G. S; ROITMAN, F. B; DE CONTI, B. M. Pronaf B: evolução e metodologias. Informativo Técnico AGRIS, Rio de Janeiro, n.2, fev. 2012. 
MATTEI, L. O papel e a importância da agricultura familiar no desenvolvimento rural brasileiro contemporâneo. Rev. Econ. NE, Fortaleza, v. 45, p. 83-91, 2014.

MUELLER, Charles C. A política agrícola no Brasil: uma visão de longo prazo. In: Secretaria de Política Agrícola do Ministério da Agricultura, Pecuária e Abastecimento. Revista de Política Agrícola. Ano XIX, Edição Especial, julho/2010, Brasília, DF.

NUNES, E. M et al. Microcrédito, infraestrutura e desenvolvimento rural: o Agroamigo investimento e custeio na agricultura familiar de territórios do rio grande do norte. Rev. Econ. NE, Fortaleza, v. 46, suplemento especial, p. 53-69, jul, 2015.

NUNES, S. P. O crédito rural do Pronaf e os recentes instrumentos de política agrícola para a agricultura familiar. Deser-Boletim Eletrônico, v. 156, p. 1-10, 2007.

REDE BRASIL ATUAL. Disponível em: https://www.redebrasilatual.com.br/economia/2019/05/governo-bolsonaro-suspende-financiamentopara-agricultura-familiar/. Acesso em: 20 Jun. 2019.

RUA, M. G. Análise de Políticas Públicas: Conceitos Básicos In: O Estudo da Política: Tópicos Selecionados. Ed. Brasília: Paralelo 15, 1998.

SOUZA, P. M; BARBÉ, L. C. Desigualdades regionais na distribuição dos financiamentos do PRONAF. Rev. Econ. NE, Fortaleza, v. 45, p. 31-43, 2014.

SILVA, A. F. Agricultura Familiar e o crédito rural PRONAF B: uma análise a partir dos beneficiários. 2017. 130f. Dissertação (Mestrado Acadêmico em Planejamento e Dinâmicas Territoriais no Semiárido) - Departamento de Economia, Universidade do Estado do Rio Grande do Norte - UERN. 